\title{
Serum adipokine profile and fatty acid composition of adipose tissues are affected by conjugated linoleic acid and saturated fat diets in obese Zucker rats
}

\author{
Susana V. Martins ${ }^{1}$, Paula A. Lopes ${ }^{1}$, Cristina M. Alfaia ${ }^{1}$, Pedro O. Rodrigues ${ }^{2}$, Susana P. Alves ${ }^{3,4}$, \\ Rui M. A. Pinto ${ }^{5}$, Matilde F. Castro ${ }^{5}$, Rui J. B. Bessa ${ }^{1,3}$ and José A. M. Prates ${ }^{1}$ \\ ${ }^{1}$ Secção de Bioquímica, CIISA, Faculdade de Medicina Veterinária, Universidade Técnica de Lisboa, Avenida da Universidade \\ Técnica, 1300-477 Lisboa, Portugal \\ ${ }^{2}$ Departamento de Bioquímica, Faculdade de Ciências Médicas, Universidade Nova de Lisboa, Campo dos Mártires da Pátria 130, \\ 1169-056 Lisboa, Portugal \\ ${ }^{3}$ Unidade de Produção Animal, L-INIA, INRB IP, Fonte Boa, 2005-048 Vale de Santarém, Portugal \\ ${ }^{4}$ REQUIMTE, ICBAS, Universidade do Porto, Rua Padre Armando Quintas, 4485-661 Vairão VC, Portugal \\ ${ }^{5}$ iMed UL, Faculdade de Farmácia, Universidade de Lisboa, Avenida Professor Gama Pinto, 1649-003 Lisboa, Portugal \\ (Received 18 June 2009 - Revised 22 September 2009 - Accepted 24 September 2009 - First published online 2 November 2009)
}

Conjugated linoleic acid (CLA) has been reported as having body fat lowering properties and the ability to modulate the inflammatory system in several models. In the present study, the effects of CLA added to saturated fat diets, from vegetable and animal origins, on the serum adipokine profile of obese Zucker rats were assessed. In addition, the fatty acid composition of epididymal and retroperitoneal adipose tissues was determined and a principal component analysis (PCA) was used to assess possible relationships between fatty acids and serum metabolites. Atherogenic diets ( $2 \%$ cholesterol) were formulated with palm oil and ovine fat and supplemented or not with $1 \%$ of a mixture (1:1) of cis-9,trans-11 and trans10,cis-12-CLA isomers. CLA-fed animals exhibited lower daily feed intake, final body and liver weights, and hepatic lipids content. Total and LDL-cholesterol levels were increased in CLA-supplemented groups. CLA also promoted higher adiponectin and lower plasminogen activator inhibitor-1 (PAI-1) serum concentrations. In contrast to palm oil diets, ovine fat increased insulin resistance and serum levels of leptin, TNF- $\alpha$ and IL-1 $\beta$. Epididymal and retroperitoneal adipose tissues had similar deposition of individual fatty acids. The PCA analysis showed that the trans-10,cis-12-CLA isomer was highly associated with adiponectin and PAI-1 levels. Summing up, CLA added to vegetable saturated enriched diets, relative to those from animal origin, seems to improve the serum profile of adipokines and inflammatory markers in obese Zucker rats due to a more favourable fatty acid composition.

Conjugated linoleic acid: Saturated diets: Adipokines: Fatty acids: Obese Zucker rats

The metabolic disorders caused by overweight are one of the major factors contributing to the increase in health care costs. Among these disorders are atherosclerosis, hypertension, insulin resistance, hypertriglyceridaemia and hypercholesterolaemia $^{(1)}$. Dysregulated endocrine function of adipose tissue, in particular of visceral compartment, leads to an increased release of hormones and pro/anti-inflammatory molecules ${ }^{(1)}$. These factors secreted by adipose tissue, although not exclusively by adipose cells ${ }^{(2)}$, are called adipokines. They include adiponectin, leptin, TNF- $\alpha$, IL- $1 \beta$ and IL-6, C-reactive protein (CRP), monocyte chemoattractant protein-1 and plasminogen activator inhibitor-1 (PAI-1), being most of them elevated in direct proportion to adiposity, except adiponectin ${ }^{(3)}$. Adiponectin, leptin and ghrelin are involved in energy balance, regulating feeding behaviour ${ }^{(4)}$. Despite ghrelin being mainly produced in the stomach, visceral adipose tissue also secretes this hormone ${ }^{(5)}$. Enhanced activities of TNF- $\alpha$ and IL- 6 are involved in the development of obesityrelated insulin resistance, and PAI-1 in the impairment of fibrinolysis $^{(6)}$. Other adipokines, like adiponectin and leptin, mitigate insulin resistance as they stimulate $\beta$-oxidation of fatty acids in skeletal muscle ${ }^{(4)}$. The understanding of adipokines molecular actions may lead to effective therapeutic strategies, ultimately designed to protect obese individuals against CVD, hypertension and type 2 diabetes.

Conjugated linoleic acid (CLA) is a group of positional and geometric isomers of linoleic acid, cis-9,cis-12-18: $2(c 9, c 12-$ 18:2), with conjugated double bonds, which modulates

Abbreviations: AST, aspartate aminotransferase; CLA, conjugated linoleic acid; c9,t11-CLA, cis-9,trans-11-CLA; t10,c12-CLA, trans-10, cis-12-CLA; CRP, C-reactive protein; HOMA-IR, homeostasis model assessment-insulin resistance; OCLA, ovine fat diet $+1 \%$ of CLA; PAI-1, plasminogen activator inhibitor-1; PC, principal components; PCLA, palm oil diet $+1 \%$ of CLA.

* Corresponding author: Susana V. Martins, fax +351 21 3652829, email smartins@fmv.utl.pt 
adiposity and related adipokine levels ${ }^{(7)}$. CLA is naturally found in foods of ruminant origin (e.g. as beef, lamb and dairy products) and is composed mainly by the cis-9, trans-11-18:2 (c9,t11-CLA) isomer, with the trans-10, cis-12-18:2 (t10,c12-CLA) isomer comprising only a small percentage ${ }^{(8)}$. It is well established that CLA has important effects on glucose and lipid metabolisms and that, especially the $t 10, c 12$-CLA isomer, is able to reduce fat deposition ${ }^{(9,10)}$. However, it has been reported that CLA, as a mixture of both isomers or its $t 10, c 12-C L A$ isomer, induces potential side effects, such as hyperinsulinaemia and insulin resistance, promoting hepatic steatosis in lean and obese mouse models $^{(11,12)}$.

Additionally to CLA's adipokine modulation, other dietary fatty acids may interfere with adipokines expression and concentration $^{(13,14)}$. Nevertheless, the relationship between CLA, adipokines and fatty acids in adipose tissue is far from clear in obese insulin-resistant models. Mutations affecting leptin action are associated with massive obesity in both human subjects and rodents ${ }^{(15)}$. For this purpose, the present study selected the falfa Zucker rat as experimental model, which develops morbid obesity due to the $f a$ mutation on the leptin receptor. These rats display mild hyperglycaemia, pronounced hyperinsulinaemia, marked reduction in insulin sensitivity and hepatic steatosis ${ }^{(16)}$.

Dietary manipulations, involving protein type and fat levels, result in complicated interactions with the fat-reducing effect of $\mathrm{CLA}^{(17)}$. This approach might help to support the beneficial effects of CLA and minimise its possible unfavourable side effects. Western diets provide a dramatic dietary fat imbalance, characterised by high percentages of saturated fats, which are among the most important causes of human mortality in developed countries ${ }^{(18)}$. To the best of our knowledge, the combination of dietary saturated fats from vegetable and animal origins with CLA effects has not been evaluated so far.

Facing this scenario, the main goal of the present study was to search for CLA and saturated fat diets effects on the serum adipokine profile of obese Zucker rats. High fat diets were formulated as atherogenic (with $2 \%$ of cholesterol) based on two distinct saturated fats (palm oil or ovine fat) alone or combined with $1 \%$ of CLA. Moreover, a principal component (PC) analysis was used in order to elucidate possible associations between the levels of individual fatty acids from adipose tissues and serum metabolites.

\section{Materials and methods}

\section{Diet ingredients}

All dietary components, except CLA oil and ovine fat, were purchased from Provimi Kliba SA (Kaiseraugst, Switzerland), which prepared and pelleted the experimental diets. The CLA oil ( $80 \%$ purity) was a generous gift of PharmaNutrients Inc. (Gurnee, IL, USA) and contained a 1:1 mixture of $c 9, t 11$ and $t 10, c 12-C L A$ isomers. The ovine intraperitoneal fat was obtained from lambs fed with pelleted dehydrated lucerne supplemented with $6 \%$ of a blend of sunflower and linseed oils ${ }^{(19)}$. The raw ovine fat was melted, and then filtered to subsequent incorporation in the diets.

\section{Animals and diets}

Experimental procedures were reviewed by the Ethics Commission of CIISA/FMV and approved by the Animal Care Committee of the National Veterinary Authority (DirecçãoGeral de Veterinária, Portugal), following the appropriated European Union guidelines (N. 86/609/EEC). Obese male Zucker rats ( $n$ 32, Harlan Interfauna Iberia, Barcelona, Spain), ageing 5 weeks old, were individually housed in cages and maintained on a $12 \mathrm{~h}$ light-dark cycle at $22 \pm 2{ }^{\circ} \mathrm{C}$. All rats had free access to tap water and semipurified atherogenic diets, based on the AIN-93G formulation. Ingredients composition (\% feed) was casein (20.0), dextrose (13.2), sucrose (11.9), maize starch (29.3), cellulose (5.0), AIN-93G vitamin mix (0.5), AIN-93G mineral mix (2.4), amino acids $(0 \cdot 3)$, cholesterol (2.0), cholic acid sodium salt $(0 \cdot 5)$ and butylated hydroxytoluene $(0 \cdot 01)$. After an acclimatisation period of 1 week, eight rats were allocated to one of the following dietary treatments: group palm oil, $11.3 \%$ of palm oil plus $3.8 \%$ sunflower oil; group palm oil diet $+1 \%$ of CLA (PCLA), $11.3 \%$ of palm oil plus $2.5 \%$ sunflower oil plus $1.2 \%$ CLA; group ovine fat, $11.3 \%$ ovine fat plus $3.8 \%$ sunflower oil; group ovine fat diet $+1 \%$ of CLA (OCLA), $11.3 \%$ ovine fat plus $2.5 \%$ sunflower oil plus $1.2 \%$ CLA. The proximate composition and fatty acid profile of the diets are shown in Table 1. Body weight and feed intake were recorded twice a week. After 14 weeks, rats were fasted for $12 \mathrm{~h}$ and killed by decapitation under light isoflurane anaesthesia. The trunk blood was centrifuged (1500 $\mathrm{g}$ for $10 \mathrm{~min}$, at room temperature) to separate serum. Following blood collection, the organs were removed, weighted and stored at $-80^{\circ} \mathrm{C}$.

\section{Serum biochemical assays}

Total cholesterol, HDL-cholesterol, LDL-cholesterol, TAG, glucose, total proteins, aspartate aminotransferase (AST, EC 2.6.1.1), alanine aminotransferase (EC 2.6.1.2) and alkaline phosphatase (EC 3.1.3.1) were analysed in serum through

Table 1. Composition and fatty acid profile of the diets

\begin{tabular}{|c|c|c|c|c|}
\hline & $P$ & PCLA & $\mathrm{O}$ & OCLA \\
\hline \multicolumn{5}{|c|}{ Proximate composition (\% DM) } \\
\hline Crude protein & 18 & 18 & 18 & 18 \\
\hline Crude fat & 15 & 15 & 15 & 15 \\
\hline Crude ash & 3.5 & 3.5 & 3.5 & 3.5 \\
\hline Crude fibre & 3.5 & 3.5 & 3.5 & 3.5 \\
\hline Nitrogen-free extract & 50 & 50 & 50 & 50 \\
\hline \multicolumn{5}{|c|}{ Fatty acid composition ( $\%$ of total FAME) } \\
\hline $14: 0$ & 0.92 & 1.00 & 1.35 & 1.34 \\
\hline $16: 0$ & 35.4 & 37.5 & $12 \cdot 6$ & $12 \cdot 3$ \\
\hline $18: 0$ & 4.23 & 4.08 & $21 \cdot 0$ & 21.5 \\
\hline$c 9-18: 1$ & 34.9 & $32 \cdot 3$ & $22 \cdot 3$ & $21 \cdot 0$ \\
\hline$t 11-18: 1$ & 0.06 & 0.06 & $9 \cdot 22$ & 9.42 \\
\hline $18: 2 n-6$ & $20 \cdot 0$ & $16 \cdot 0$ & $15 \cdot 7$ & $12 \cdot 2$ \\
\hline $18: 3 n-3$ & 0.14 & 0.11 & 1.23 & 1.24 \\
\hline$c 9, t 11-C L A$ & 0.02 & 2.48 & 1.32 & 3.51 \\
\hline$t 10, c 12-C L A$ & 0.01 & 2.47 & ND & $2 \cdot 10$ \\
\hline Others & 4.38 & 4.00 & $15 \cdot 3$ & $15 \cdot 4$ \\
\hline
\end{tabular}

Dietary treatments: $P$, palm oil diet; PCLA, palm oil diet $+1 \%$ of conjugated linoleic acid; $\mathrm{O}$, ovine fat diet; OCLA, ovine fat diet $+1 \%$ of conjugated linoleic acid; ND, not detected; FAME, fatty acid methyl esters; CLA, conjugated linoleic acid. 
diagnostic test kits (Roche Diagnostics, Mannheim, Germany), using a Modular Hitachi Analytical System (Roche Diagnostics). VLDL-cholesterol and total lipids were calculated according to Friedewald et al. ${ }^{(20)}$ and Covaci et al. ${ }^{(21)}$ formulas, respectively.

Insulin, leptin, IL-1 $\beta$, IL-6, TNF- $\alpha$, monocyte chemoattractant protein-1 and total PAI-1 concentrations in serum were determined simultaneously through the Rat Serum Adipokine LINCOplex kit (RADPK-81K, Linco Research, Millipore, MA, USA), using the Luminex xMAP technology (Lincoplex 200, Linco Research). Adiponectin (EZRADP62K, Linco Research), ghrelin (EZRGRT-91K, Linco Research) and CRP (CYT 294, Chemicon International, Millipore) levels were measured using commercial ELISA kits.

The degree of insulin resistance was calculated by the homeostasis model assessment using the insulin resistance index $\left(\right.$ HOMA-IR) ${ }^{(22)}$ : fasting serum glucose $(\mathrm{mmol} / \mathrm{l})$ times fasting serum insulin (mU/l) divided by $22 \cdot 5$. Low HOMAIR values indicate high insulin sensitivity, whereas high HOMA-IR values indicate high insulin resistance.

\section{Hepatic lipid extraction}

After liver lyophilisation, total lipids were extracted in duplicate, and gravimetrically measured using the procedure described by Fritsche et al. ${ }^{(23)}$. Briefly, lipids were extracted three times with methylene chloride-methanol $(4: 1 \mathrm{v} / \mathrm{v})$ and a fourth time with $n$-hexane. Following evaporation and dry, the fatty residue was weighted.

\section{Fatty acid composition of adipose tissues}

Fatty acids methyl esters from epididymal and retroperitoneal adipose tissues were obtained using the method of Christie et al. ${ }^{(24)}$, slightly modified by Raes et al. ${ }^{(25)}$. In short, $1 \mathrm{ml}$ dry toluene was added to $0.05 \mathrm{~g}$ of lyophilised samples, and fatty acids were methylated through a base catalysis followed by an acid catalysis. At $50^{\circ} \mathrm{C}$, sodium methoxide in anhydrous methanol $(0.5 \mathrm{~mol} / \mathrm{l})$ reacted for $30 \mathrm{~min}$, followed by $\mathrm{HCl}$ in methanol $(1: 1 \mathrm{v} / \mathrm{v})$ for $10 \mathrm{~min}$. fatty acids methyl esters were extracted twice with $3 \mathrm{ml} n$-hexane, and pooled extracts were evaporated until $2 \mathrm{ml}$ volume under a stream of nitrogen. The resulting fatty acids methyl esters were then analysed by GC, using a fused-silica capillary column (CP-Sil 88; $100 \mathrm{~m} \times 0.25 \mathrm{~mm}$ inner diameter $\times 0.20 \mathrm{~mm}$ film thickness; Chrompack, Varian Inc., Walnut Creek, CA, USA), equipped with a flame ionisation detector. The chromatographic conditions were described in detail by Jerónimo et al. ${ }^{(19)}$. Fatty acid composition was expressed as $\mathrm{g} / 100 \mathrm{~g}$ of total fatty acids identified. The fatty acid composition of diets was obtained following the same analytical procedure described for adipose tissues.

\section{Statistical analysis}

Statistical analysis was carried out with the Statistical Analysis Systems software package, version 9.1 (SAS Institute, Cary, NC, USA). All data were reported as means with their standard errors. The proc GLM procedure was used to perform a $2 \times 2$ factorial analysis to determine significant main effects of CLA, fat source and their interaction (CLA $\times$ fat). When the interaction effect was significant, differences between groups were calculated using Tukey's post hoc test at $P<0.05$.

In order to evaluate differences between fatty acid composition from epididymal and retroperitoneal adipose tissues, the proc GLM procedure was used with tissue as a single factor. Afterwards, PC analysis was performed, using proc PRINCOMP of SAS, to assess relationships between fatty acids (average between fatty acids from epididymal and retroperitoneal adipose tissues) and adipokines. After data normalisation, the analysis was based on the correlation matrix (consisting of twenty-nine variables) and PC were considered as significant if they contributed more than $5 \%$ for the total variance.

\section{Results}

\section{Body composition}

The daily feed intake and body weight, as well as both adipose tissues and liver weights, are presented in Table 2. CLA-fed rats had lower final body weight due, in part, to a decrease in the average daily intake induced by CLA $(P<0 \cdot 01)$. In the same manner, liver weight and hepatic lipids were reduced in PCLA and OCLA groups in relation to their matching groups $(P<0.001)$. In contrast, neither CLA nor fat source had any effect on the weight of epididymal and retroperitoneal adipose tissues $(P>0.05)$. The interaction CLA $\times$ fat was not observed for any of those parameters $(P>0 \cdot 05)$. Finally, the weight of longissimus dorsi muscle, kidney, testicle, spleen, heart and lung did not present statistical differences $(P>0 \cdot 05$, data not shown).

\section{Serum metabolite profile}

The serum metabolite profile is also listed on Table 2. Animals fed CLA had higher levels of total and LDL-cholesterol $(P<0.05)$ and lower glucose levels $(P<0.05)$. Insulin and HOMA-IR were higher in ovine fat groups compared with palm oil groups $(P<0.05)$, but were not affected by CLA $(P>0 \cdot 05)$. Regarding the hepatic enzymes, lower circulating AST concentrations were found for CLA-supplemented animals $(P<0 \cdot 05)$. CLA enhanced adiponectin levels $(P<0.001)$ regardless the fat source. Leptin levels were affected by the fat source but not by the supplementation with CLA, being higher in ovine fat groups $(P<0 \cdot 001)$. Neither CLA nor fat source had effects on ghrelin concentrations $(P>0.05)$. The changes in the pro-inflammatory markers IL-1 $\beta$, IL-6, TNF- $\alpha$ and CRP are also summarised on Table 2. IL-1 $\beta$ and TNF- $\alpha$ were affected by the fat source independently of CLA supplementation, being higher in ovine fat groups $(P<0 \cdot 05)$. IL-6 was dependent on the interaction between CLA and fat source. OCLA group presented higher values of IL-6 than the other dietary treatments $(P<0 \cdot 05)$. CRP and monocyte chemoattractant protein-1 levels were similar for all dietary groups $(P>0.05)$. In contrast, CLA reduced PAI-1 concentrations regardless the fat source $(P<0 \cdot 01)$. 
Table 2. Body composition variables and serum metabolites

\begin{tabular}{|c|c|c|c|c|c|c|c|c|}
\hline & \multirow[b]{2}{*}{$P$} & \multirow[b]{2}{*}{ PCLA } & \multirow[b]{2}{*}{$\mathrm{O}$} & \multirow[b]{2}{*}{ OCLA } & \multirow[b]{2}{*}{ SEM } & \multicolumn{3}{|c|}{ Significance level } \\
\hline & & & & & & CLA & Fat & $C L A \times$ fat \\
\hline \multicolumn{9}{|l|}{ Growth and body composition } \\
\hline Initial body weight $(\mathrm{g})$ & 240 & 234 & 234 & 234 & $11 \cdot 2$ & NS & NS & NS \\
\hline Final body weight (g) & 577 & 552 & 584 & 511 & $12 \cdot 7$ & $* * *$ & NS & NS \\
\hline Daily feed intake (g/d) & $23 \cdot 7$ & $23 \cdot 0$ & 23.9 & $21 \cdot 8$ & 0.508 & $\star \star \star ~$ & NS & NS \\
\hline Retroperitoneal fat weight (g) & 24.0 & $24 \cdot 7$ & $23 \cdot 7$ & $20 \cdot 7$ & 1.62 & NS & NS & NS \\
\hline Epididymal fat weight (g) & 13.7 & $15 \cdot 2$ & $14 \cdot 7$ & $14 \cdot 6$ & 0.605 & NS & NS & NS \\
\hline Liver weight (g) & $62 \cdot 2$ & $54 \cdot 7$ & $60 \cdot 6$ & $48 \cdot 1$ & 1.88 & $* \star *$ & * & NS \\
\hline Hepatic lipids (\% liver weight) & 21.9 & $18 \cdot 9$ & 23.5 & $19 \cdot 2$ & $0 \cdot 800$ & $\star \star \star *$ & NS & NS \\
\hline \multicolumn{9}{|l|}{ Serum biochemistry profile } \\
\hline Total cholesterol (mg/l) & 11719 & 15173 & 13705 & 16271 & 1333 & * & NS & NS \\
\hline HDL-cholesterol (mg/l) & 1811 & 1759 & 1901 & 1849 & 101 & NS & NS & NS \\
\hline LDL-cholesterol (mg/l) & 7485 & 10001 & 9205 & 10526 & 876 & * & NS & NS \\
\hline VLDL-cholesterol $(\mathrm{mg} / \mathrm{l}) \dagger$ & 885 & 1211 & 870 & 1061 & 169 & NS & NS & NS \\
\hline TAG $(\mathrm{mg} / \mathrm{l})$ & 4425 & 6068 & 4373 & 5299 & 844 & NS & NS & NS \\
\hline Total lipids (mg/l)‡ & 20490 & 26543 & 23557 & 26751 & 2421 & NS & NS & NS \\
\hline Total proteins $(\mathrm{g} / \mathrm{l})$ & 78.7 & 71.7 & $75 \cdot 8$ & $70 \cdot 2$ & 3.26 & NS & NS & NS \\
\hline Glucose $(\mathrm{mg} / \mathrm{l})$ & 1155 & 1061 & 1226 & 1076 & $56 \cdot 6$ & * & NS & NS \\
\hline Insulin (ng/ml) & 1.78 & 1.84 & 3.02 & 2.53 & 0.26 & NS & ** & NS \\
\hline HOMA-IR $(\mathrm{mmol} / \mathrm{l} \times \mathrm{mU} / \mathrm{l}) \S$ & $14 \cdot 1$ & $14 \cdot 4$ & $25 \cdot 5$ & $18 \cdot 4$ & $2 \cdot 68$ & NS & * & NS \\
\hline \multicolumn{9}{|l|}{ Serum hepatic markers } \\
\hline AST (U/I) & 355 & 287 & 341 & 240 & $37 \cdot 7$ & * & NS & NS \\
\hline $\operatorname{ALT}(\mathrm{U} / \mathrm{l})$ & $69 \cdot 4$ & $85 \cdot 9$ & $78 \cdot 0$ & 88.9 & 6.93 & NS & NS & NS \\
\hline ALP (U/I) & 284 & 283 & 226 & 237 & $33 \cdot 2$ & NS & NS & NS \\
\hline \multicolumn{9}{|l|}{ Serum adipokine profile } \\
\hline Adiponectin $(\mu \mathrm{g} / \mathrm{ml})$ & 11.6 & $15 \cdot 3$ & $10 \cdot 9$ & 14.6 & 0.716 & $\star \star \star \star$ & NS & NS \\
\hline Leptin (ng/ml) & 3.61 & 3.03 & $6 \cdot 22$ & 5.48 & 0.688 & NS & $\star \star \star ~$ & NS \\
\hline Ghrelin (ng/ml) & 1.22 & 1.06 & 0.75 & 1.06 & 0.184 & NS & NS & NS \\
\hline $\mathrm{IL}-1 \beta(\mathrm{pg} / \mathrm{ml})$ & 175 & 196 & 451 & 448 & 49.4 & NS & $\star * \star$ & NS \\
\hline IL-6 (pg/ml) & $165^{\mathrm{b}}$ & $148^{\mathrm{b}}$ & $179^{\mathrm{b}}$ & $259^{\mathrm{a}}$ & $20 \cdot 5$ & NS & ** & * \\
\hline TNF- $\alpha(\mathrm{pg} / \mathrm{ml})$ & $24 \cdot 1$ & $24 \cdot 4$ & 24.9 & $25 \cdot 7$ & 0.411 & NS & * & NS \\
\hline CRP (pg/ml) & 250 & 320 & 286 & 292 & $33 \cdot 7$ & NS & NS & NS \\
\hline MCP-1 (pg/ml) & 561 & 455 & 371 & 588 & 100 & NS & NS & NS \\
\hline PAl-1 (pg/ml) & 370 & 243 & 560 & 202 & $77 \cdot 0$ & ** & NS & NS \\
\hline
\end{tabular}

Dietary treatments: P, palm oil diet; PCLA, palm oil diet $+1 \%$ of conjugated linoleic acid; $\mathrm{O}$, ovine fat diet; OCLA, ovine fat diet $+1 \%$ of conjugated linoleic acid.

AST, aspartate aminotransferase (EC 2.6.1.1); ALT, alanine aminotransferase (EC 2.6.1.2); ALP, alkaline phosphatase (EC 3.1.3.1); CRP, C-reactive protein; MCP-1, monocyte chemoattractant protein-1; PAl-1, plasminogen activator inhibitor-1.

Mean values were significant: NS, $P>0.05$, ${ }^{\star} P<0.05,{ }^{\star \star} P<0.01,{ }^{\star * \star} P<0.001$

${ }_{\mathrm{a}, \mathrm{b}}$ Mean values within the same row with different superscript letters are statistically different (Tukey's post hoc test, $P<0.05$ ).

$\dagger$ VLDL-cholesterol $=1 / 5($ TAG)

$\ddagger$ Total lipids $=($ total cholesterol $) \times 1.12+($ TAG $) \times 1.33+148$.

$\S$ HOMA-IR, insulin resistance index $=$ (fasting serum glucose $) \times($ fasting serum insulin)/22.5.

Fatty acid composition of epididymal and retroperitoneal adipose tissues

The fatty acid composition of epididymal and retroperitoneal adipose tissues are presented in Tables 3 and 4, respectively. In both tissues, the effect of fat source was detected for all fatty acids $(P<0 \cdot 001)$. Palm oil groups were richer in $16: 0$, $c 9-16: 1, c 9-18: 1,18: 2 n-6$ and $20: 4 n-6$ fatty acids than ovine fat groups $(P<0 \cdot 001)$. Rats fed ovine fat presented higher values of $14: 0, c 7-16: 1,18: 0, t 10+t 11-18: 1$, $18: 3 n-3$ and CLA isomers than groups fed palm oil $(P<0 \cdot 001)$. CLA-fed rats had more $c 7-16: 1$ and $t 10+t 11$ $18: 1$, and less $c 9-18: 1,18: 2 n-6$ and $20: 4 n-6$ fatty acids $(P<0 \cdot 001)$. Moreover, CLA supplementation increased the percentages of $c 9, t 11$-CLA comparing with their matching groups $(P<0.001)$ in both adipose tissues. Also, $t 10$, $c 12$-CLA isomer and the other CLA isomers were increased in PCLA and OCLA groups $(P<0.001)$, but in a lower magnitude. About fatty acids sums, CLA had no effect on total SFA $(P>0.05)$ from epididymal adipose tissue, but increased it in retroperitoneal adipose tissue $(P<0 \cdot 05)$.
Total MUFA and total PUFA had lower percentages in CLA-fed rats $(P<0 \cdot 001)$. In both tissues, the $\Delta 9$-indices were affected by CLA $\times$ fat interaction $(P<0 \cdot 05)$. The $\Delta 9$-index16 ratio was higher in $\mathrm{O}$ group than the others $(P<0.05)$, and palm oil and PCLA groups had higher $\Delta 9$-index 18 ratio than ovine fat groups $(P<0 \cdot 05)$. As shown in Tables 3 and 4 , the response of fatty acid composition in epididymal adipose tissue had a similar pattern as the one described for retroperitoneal adipose tissue. This fact was confirmed by the ANOVA with a single factor. Only $c 9-16: 1$ and $c 11-18: 1$ fatty acids had differences between adipose tissues $(P<0.001$; data not shown). Due to this similarity, the subsequent PC statistical analysis was performed using the average values of fatty acids from epididymal and retroperitoneal adipose tissues.

\section{Principal component analyses}

The results of PC analysis of fatty acid composition of adipose tissues and serum metabolites are shown in Table 5. The five 
Table 3. Fatty acid composition (\% of total fatty acids methyl esters (FAME)) of epididymal adipose tissue

\begin{tabular}{|c|c|c|c|c|c|c|c|c|}
\hline & \multirow[b]{2}{*}{$P$} & \multirow[b]{2}{*}{ PCLA } & \multirow[b]{2}{*}{$\mathrm{O}$} & \multirow[b]{2}{*}{ OCLA } & \multirow[b]{2}{*}{ SEM } & \multicolumn{3}{|c|}{ Significance level } \\
\hline & & & & & & CLA & Fat & $C L A \times$ fat \\
\hline $14: 0$ & 1.05 & 1.24 & 1.30 & 1.42 & 0.020 & 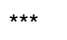 & 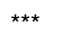 & NS \\
\hline $16: 0$ & $25 \cdot 2$ & 25.69 & $18 \cdot 80$ & 19.00 & 0.167 & NS & $\star \star * *$ & NS \\
\hline$c 7-16: 1$ & 0.42 & 0.51 & 0.52 & 0.66 & 0.013 & $\star \star \star *$ & $\star * \star *$ & NS \\
\hline$c 9-16: 1$ & $7.59^{a}$ & $7 \cdot 87^{a}$ & $6 \cdot 67^{\mathrm{b}}$ & $6 \cdot 18^{\mathrm{C}}$ & 0.111 & NS & $* * *$ & ** \\
\hline $18: 0$ & $1.98^{\mathrm{b}}$ & $1.77^{\mathrm{b}}$ & $4 \cdot 19^{a}$ & $4 \cdot 27^{a}$ & 0.065 & NS & $\star * *$ & * \\
\hline$c 9-18: 1$ & $40 \cdot 9$ & 39.4 & 36.5 & $35 \cdot 3$ & 0.198 & $* \star *$ & *** & NS \\
\hline$c 11-18: 1$ & $4.67^{b}$ & $4.91^{\mathrm{a}}$ & $4.75^{\mathrm{b}}$ & $4.59^{b}$ & 0.052 & NS & ** & $* \star * *$ \\
\hline$t 10+t 11-18: 1$ & ND & 0.31 & 3.30 & 3.53 & 0.044 & 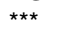 & 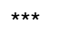 & NS \\
\hline $18: 2 n-6$ & $15 \cdot 3$ & $13 \cdot 3$ & $13 \cdot 8$ & $12 \cdot 2$ & 0.155 & $* * *$ & $* * *$ & NS \\
\hline $18: 3 n-3$ & 0.17 & 0.16 & 0.77 & 0.74 & 0.014 & NS & 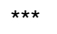 & NS \\
\hline$c 9, t 11-C L A$ & ND & $1.55^{\mathrm{C}}$ & $2 \cdot 37^{\mathrm{b}}$ & $4.09^{a}$ & 0.038 & $\star \star \star \star ~$ & $\star \star \star *$ & * \\
\hline$t 10, c 12-C L A$ & ND & 0.58 & 0.15 & 0.72 & 0.016 & $\star \star * \star$ & $\star \star * *$ & NS \\
\hline CLA others & ND & $0.03^{b}$ & ND & $0.26^{a}$ & 0.005 & $* * *$ & $\star \star \star \star ~$ & $\star \star \star *$ \\
\hline $20: 4 n-6$ & 0.67 & 0.31 & 0.56 & 0.25 & 0.017 & 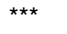 & $\star \star \star \star ~$ & NS \\
\hline Total FAME & 98.1 & $97 \cdot 6$ & $93 \cdot 7$ & 93.3 & 0.079 & 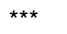 & $\star \star \star *$ & NS \\
\hline Others & 1.95 & 2.45 & $6 \cdot 33$ & $6 \cdot 72$ & 0.079 & 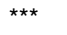 & $\star \star \star *$ & NS \\
\hline SFAt & $28 \cdot 3$ & $28 \cdot 7$ & $24 \cdot 3$ & $24 \cdot 7$ & 0.206 & NS & $\star \star \star *$ & NS \\
\hline MUFA & 53.6 & $52 \cdot 7$ & 48.4 & $46 \cdot 8$ & 0.216 & 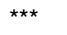 & $* * \star$ & NS \\
\hline PUFA§ & $16 \cdot 2$ & $13 \cdot 7$ & $15 \cdot 2$ & $13 \cdot 2$ & 0.162 & 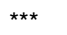 & $\star \star * *$ & NS \\
\hline Total CLA\| & ND & $2 \cdot 16^{\mathrm{C}}$ & $2 \cdot 51^{\mathrm{b}}$ & $5 \cdot 07^{\mathrm{a}}$ & 0.051 & 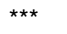 & $\star * \star *$ & 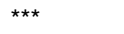 \\
\hline$\Delta 9$-index16 & $1 \cdot 30^{\mathrm{b}}$ & $1.31^{b}$ & $1 \cdot 36^{a}$ & $1 \cdot 33^{b}$ & 0.007 & NS & $\star * \star$ & * \\
\hline$\Delta 9$-index18†† & $21 \cdot 8^{\mathrm{b}}$ & $23 \cdot 4^{\mathrm{a}}$ & $9 \cdot 74^{\mathrm{C}}$ & $9 \cdot 28^{c}$ & 0.356 & NS & $\star \star * *$ & * \\
\hline
\end{tabular}

Dietary treatments: $\mathrm{P}$, palm oil diet; PCLA, palm oil diet $+1 \%$ of conjugated linoleic acid; O, ovine fat diet; OCLA, ovine fat diet $+1 \%$ of conjugated linoleic acid. ND, not detected.

Mean values were significant: NS, $P>0.05,{ }^{*} P<0.05,{ }^{\star \star} P<0.01,{ }^{\star * \star} P<0.001$.

a,b,c Mean values within the same row with different superscript letters are statistically different (Tukey's post hoc test, $P<0.05)$.

†SFA $=$ sum of $14: 0,16: 0$ and $18: 0$.

$\ddagger$ MUFA $=$ sum of $c 7-16: 1, c 9-16: 1, c 9-18: 1$ and $c 11-18: 1$

§PUFA $=$ sum of $18: 2 n-6,18: 3 n-3$ and $20: 4 n-6$.

$\|$ Total CLA $=$ sum of $c 9, t 11-C L A, t 10, c 12-C L A$ and CLA others

I $\triangle 9$-index16, desaturation index $16: 0$ to $16: 1=16: 0 /(16: 0+c 9-16: 1)$

†† $\Delta 9$-index 18 , desaturation index $18: 0$ to $18: 1=18: 0 /(18: 0+c 9-18: 1)$.

first PC explained $87.56 \%$ of the total variance. The first and second PC were responsible for $63.48 \%$ of the total variance, 43.85 and $19.63 \%$, respectively. The PC3 explained $10.08 \%$, the PC4 $7.64 \%$ and the PC5 $6.36 \%$ of the variability. As total variance explained by the first two PC is greater than $50 \%$, the projection of fatty acids and serum metabolites in the plane defined by these PC is shown in Fig. 1. Overall, PC1 was mainly characterised by $16: 0(0.84), c 9-16: 1(0.88)$ and $c 9-18: 1(0.97)$ fatty acids on the right side and by $14: 0$ $(-0.83), c 7-16: 1(-0.94), 18: 0(-0.91), t 10+t 11-18: 1$ $(-0.94), c 9, t 11-$ CLA $(-0.97)$ and $18: 3 n-3(-0.88)$ fatty acids on the left side. The fatty acids $16: 0$ and $c 9-16: 1$, mainly found in palm oil diets, are in opposition to $18: 0$ and 18:1 trans fatty acids, mainly found in ovine fat diets (Table 1). Therefore, PC1 discriminated between fatty acids associated with palm oil and ovine fat added to the diets. The PC2 clearly distinguished $t 10, c 12$-CLA isomer $(0.71)$ and adiponectin $(0.71)$, located in the upper part, from PAI-1 (-0.76) and 20:4n-6 (-0.68), located in the lower part of the graphic. As $c 9, t 11-$ CLA isomer was already present in the ovine fat diets and the only source of $t 10, c 12-C L A$ isomer was the supplementation, the PC2 discriminated between CLA supplementation and no CLA supplementation. In quadrant $\mathrm{A}$, a group was defined by $c 9, t 11-\mathrm{CLA}$ isomer, other CLA isomers, 14:0, $c 7-16: 1$ and TNF- $\alpha$. In quadrant $\mathrm{B}$, another group was distinguished, composed by $c 9-16: 1$, $c 9-18: 1, \quad c 11-18: 1$ and ghrelin. The fatty acids 18:0, $18: 3 n-3$ and $t 10+t 11-18: 1$, which showed enhanced values in ovine fat-fed animals, appeared grouped in quadrant $\mathrm{D}$ and highly correlated with leptin, IL-1 $\beta$ and insulin. Interestingly, this group of adipokines was opposed to 16:0; the $t 10, c 12-C L A$ isomer was opposed to $20: 4 n-6$ and PAI-1; and the $c 9, t 11$-CLA isomer opposed to TAG. The variables with higher loadings were HDL-cholesterol (-0.74), IL-6 $(-0.68)$ and CRP (0.71) in PC3; total-cholesterol (-0.63), TAG $(-0.65)$ and glucose $(0.63)$ in PC4; and adiponectin $(-0 \cdot 48)$ in PC5.

\section{Discussion}

The present investigation showed that animals fed CLA, regardless the fat source, gained less body weight, in parallel with a reduction in liver weight and hepatic lipids content. A decrease in daily feed intake by CLA was also observed, yet this variation seems insufficient to fully explain the variations in final body weight. Taking into account the conversion of food ingested on the weight gain, the average was 7.0 and $7.2 \mathrm{~g}$ food/g weight for palm oil and ovine fat groups. As the difference in feed intake was 68.6 and $205.8 \mathrm{~g}$ for palm oil diet/PCLA and ovine fat diet/OCLA groups, respectively, only 9.8 and $28.6 \mathrm{~g}$ of the total weight gain is explained by the food, remaining to justify 15.2 and $44.4 \mathrm{~g}$. In view of the fact that no other tissues weight were affected (though subcutaneous fat was not collected due to isolation difficulties), liver was likely the organ responsible for the less weight gain. It was also observed that the decrease 
Table 4. Fatty acid composition (\% of total fatty acids methyl esters (FAME)) of retroperitoneal adipose tissue

\begin{tabular}{|c|c|c|c|c|c|c|c|c|}
\hline & \multirow[b]{2}{*}{$P$} & \multirow[b]{2}{*}{ PCLA } & \multirow[b]{2}{*}{$\mathrm{O}$} & \multirow[b]{2}{*}{ OCLA } & \multirow[b]{2}{*}{ SEM } & \multicolumn{3}{|c|}{ Significance level } \\
\hline & & & & & & CLA & Fat & $C L A \times$ fat \\
\hline $14: 0$ & $1.07^{c}$ & $1 \cdot 27^{b}$ & $1.40^{\mathrm{a}}$ & $1.48^{\mathrm{a}}$ & 0.024 & $\star \star \star *$ & $* * *$ & * \\
\hline $16: 0$ & $25 \cdot 1$ & $25 \cdot 8$ & $18 \cdot 1$ & 18.4 & 0.180 & $\star \star *$ & 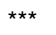 & NS \\
\hline$c 7-16: 1$ & 0.40 & 0.52 & 0.55 & 0.70 & 0.009 & *** & $\star * \star$ & NS \\
\hline$c 9-16: 1$ & $6 \cdot 81^{\mathrm{a}}$ & $6 \cdot 80^{\mathrm{a}}$ & $6.09^{b}$ & $5 \cdot 37^{c}$ & 0.114 & ** & $* * *$ & $* *$ \\
\hline $18: 0$ & $1.95^{\mathrm{b}}$ & $1.72^{b}$ & $4 \cdot 35^{a}$ & $4 \cdot 38^{a}$ & 0.061 & NS & $\star * *$ & * \\
\hline$c 9-18: 1$ & $40 \cdot 0$ & $39 \cdot 1$ & $35 \cdot 8$ & $35 \cdot 0$ & 0.129 & 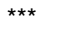 & 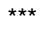 & NS \\
\hline$c 11-18: 1$ & 5.91 & 6.01 & $5 \cdot 37$ & 5.46 & 0.096 & NS & $\star \star \star *$ & NS \\
\hline$t 10+t 11-18: 1$ & ND & 0.29 & 3.64 & 3.78 & 0.046 & $\star \star \star *$ & $* * *$ & NS \\
\hline $18: 2 n-6$ & $15 \cdot 6^{\mathrm{a}}$ & $13 \cdot 1^{c}$ & $13 \cdot 9^{b}$ & $12 \cdot 2^{d}$ & 0.134 & $\star \star \star *$ & 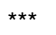 & $\star \star *$ \\
\hline $18: 3 n-3$ & 0.12 & 0.10 & 0.73 & 0.69 & 0.010 & ** & *** & NS \\
\hline$c 9, t 11-C L A$ & $0.05^{d}$ & $1 \cdot 70^{\mathrm{C}}$ & $2 \cdot 51^{\mathrm{b}}$ & $4 \cdot 39^{a}$ & 0.032 & $\star \star \star *$ & $* * *$ & ** \\
\hline$t 10, c 12-\mathrm{CLA}$ & ND & 0.62 & 0.16 & 0.75 & 0.018 & *** & $\star \star \star *$ & NS \\
\hline CLA others & ND & $0.05^{\mathrm{b}}$ & ND & $0.32^{\mathrm{a}}$ & 0.009 & $\star \star * *$ & $* * *$ & $* * *$ \\
\hline $20: 4 n-6$ & $0.73^{\mathrm{a}}$ & $0.29^{c}$ & $0.62^{b}$ & $0 \cdot 27^{c}$ & 0.017 & 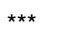 & $* * *$ & * \\
\hline Total FAME & $97 \cdot 7$ & 97.4 & $93 \cdot 2$ & $93 \cdot 1$ & 0.129 & NS & 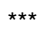 & NS \\
\hline Others & $2 \cdot 34$ & $2 \cdot 65$ & $6 \cdot 83$ & $6 \cdot 89$ & 0.129 & NS & 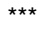 & NS \\
\hline SFAt & 28.1 & 28.8 & 23.8 & $24 \cdot 2$ & 0.211 & * & $\star \star \star *$ & NS \\
\hline MUFA & $53 \cdot 1$ & $52 \cdot 4$ & $47 \cdot 8$ & $46 \cdot 5$ & $0 \cdot 162$ & $\star \star \star ~$ & 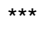 & NS \\
\hline PUFA§ & $16 \cdot 4^{\mathrm{a}}$ & $13 \cdot 5^{\mathrm{c}}$ & $15 \cdot 3^{\mathrm{b}}$ & $13 \cdot 2^{c}$ & 0.138 & 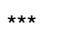 & $* * *$ & $\star * *$ \\
\hline Total CLA\| & $0.05^{d}$ & $2 \cdot 38^{\mathrm{c}}$ & $2 \cdot 67^{b}$ & $5 \cdot 46^{\mathrm{a}}$ & 0.042 & $\star \star \star *$ & *** & $\star \star \star *$ \\
\hline$\Delta 9$-index16 & $1 \cdot 27^{\mathrm{bc}}$ & $1.26^{\mathrm{C}}$ & $1 \cdot 34^{a}$ & $1 \cdot 29^{\mathrm{b}}$ & 0.006 & *** & 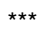 & $\star \star *$ \\
\hline$\Delta 9$-index18†† & $21.5^{\mathrm{b}}$ & $23 \cdot 7^{\mathrm{a}}$ & $9 \cdot 25^{\mathrm{c}}$ & $8.98^{\mathrm{C}}$ & 0.330 & $\star *$ & $\star \star \star *$ & $\star \star \star *$ \\
\hline
\end{tabular}

Dietary treatments: $\mathrm{P}$, palm oil diet; PCLA, palm oil diet $+1 \%$ of conjugated linoleic acid; $\mathrm{O}$, ovine fat diet; OCLA, ovine fat diet $+1 \%$ of conjugated linoleic acid. ND, not detected.

Mean values were significant: NS, $P>0.05,{ }^{*} P<0.05$, ${ }^{* \star} P<0.01,{ }^{\star \star \star} P<0.001$.

$\mathrm{a}, \mathrm{b}, \mathrm{c}, \mathrm{d}$ Mean values within the same row with different superscript letters are statistically different (Tukey's post hoc test, $P<0.05)$.

†SFA $=$ sum of $14: 0,16: 0$ and $18: 0$

† MUFA $=$ sum of $c 7-16: 1, c 9-16: 1, c 9-18: 1$ and $c 11-18: 1$.

$\S$ PUFA $=$ sum of $18: 2 n-6,18: 3 n-3$ and $20: 4 n-6$.

$\|$ Total CLA $=$ sum of $c 9, t 11-C L A, t 10, c 12-C L A$ and CLA others.

If $\triangle 9$-index 16 , desaturation index $16: 0$ to $16: 1=16: 0 /(16: 0+c 9-16: 1)$.

†† $\Delta 9$-index18, desaturation index $18: 0$ to $18: 1=18: 0 /(18: 0+c 9-18: 1)$.

in feed intake by CLA was not mediated by ghrelin. In agreement with the present findings, other authors ${ }^{(26-29)}$ have reported a reduction in hepatic lipids content by CLA and similar adipose tissue weights.

Some authors reported CLA beneficial effects in obese Zucker rats by increasing plasma adiponectin levels and, therefore, alleviating hyperinsulinaemia ${ }^{(26,30)}$. Indeed, in the present study, CLA increased adiponectin and decreased glucose levels without affecting insulin homeostasis. Instead, higher insulin and HOMA-IR values were found in rats fed ovine fat compared with rats fed palm oil. In this regard, the fat source effect in ovine fat diets, by rising up insulin levels, could overlap CLA reducing glucose effects. Also, independently of CLA supplementation, ovine fat diets increased the inflammatory markers TNF- $\alpha$ and IL- $1 \beta$, although IL-6 only increased in the OCLA group. These inflammatory changes in ovine fat groups appeared insufficient to increase CRP and monocyte chemoattractant protein-1 serum levels. In the present study, CLA had no effects on leptin levels, but ovine fat-based diets increased this adipokine. In contrast, Noto et al. ${ }^{(30)}$ and Halade et al. ${ }^{(12)}$ observed the ability of CLA to reduce leptin in serum.

Alessi et al. ${ }^{(31)}$ reported that plasma levels of PAI-1 are closely related to the degree of liver steatosis than to the fat accumulation in adipose tissue. In the present work, PAI-1 showed lower levels in CLA-supplemented groups, which possibly resulted from a decrease in hepatic lipids content. Serum levels of AST and alanine aminotransferase are normally increased in steatotic liver cases, and a stronger correlation between PAI-1 and AST rather than with alanine aminotransferase was reported by Alessi et al. ${ }^{(31)}$. In fact, our animals fed with CLA had a concomitant decrease in AST and PAI-1.

The administration of atherogenic diets allowed us to exploit if CLA is able to reverse the adverse affects of cholesterol, namely, in serum lipid profile and attenuating hepatic steatosis. Regarding the content of cholesterol in lipoproteins, CLA reduced VLDL and LDL fractions as well as total cholesterol in obese Zucker rats ${ }^{(27)}$. However, CLA induced the development of aortic fatty streaks in C57BL/6J mice $^{(32)}$. Surprisingly, in the present study, CLA increased total and LDL-cholesterol without affecting serum TAG. The changes found for cholesterol profile and PAI-1 led us to look for possible alterations in aorta microvasculature. The histological examination of different transversal segments of those aortas revealed only small morphological changes affecting smooth muscle cells, but no atheroma plaques were observed for any dietary group (images not shown).

The fatty acid composition of epididymal and retroperitoneal adipose tissues showed similar patterns. CLA induced an increase in $c 7-16: 1$ and $t 10+t 11-18: 1$ and a decrease in $c 9-18: 1,18: 2 n-6$ and $20: 4 n-6$ fatty acids. Sunflower oil 
Table 5. Loadings for the first five principal components (PC)

\begin{tabular}{|c|c|c|c|c|c|}
\hline Variables & $P C 1$ & PC2 & PC3 & $\mathrm{PC} 4$ & PC5 \\
\hline $14: 0$ & $-0.83^{*}$ & 0.22 & 0.42 & -0.09 & -0.04 \\
\hline $16: 0$ & $0.84^{\star}$ & 0.49 & -0.02 & 0.09 & -0.11 \\
\hline$c 7-16: 1$ & $-0.94^{\star}$ & 0.23 & 0.02 & -0.18 & -0.09 \\
\hline$c 9-16: 1$ & $0.88^{*}$ & 0.16 & 0.12 & -0.27 & -0.20 \\
\hline $18: 0$ & $-0.91^{\star}$ & -0.36 & 0.00 & 0.06 & 0.13 \\
\hline$c 9-18: 1$ & $0.97^{\star}$ & 0.12 & -0.13 & -0.01 & -0.06 \\
\hline$c 11-18: 1$ & 0.74 & -0.04 & 0.12 & -0.22 & -0.29 \\
\hline$t 10+t 11-18: 1$ & $-0.94^{\star}$ & -0.29 & 0.08 & -0.01 & $0 \cdot 10$ \\
\hline $18: 2 n-6$ & 0.75 & -0.56 & -0.27 & 0.16 & 0.04 \\
\hline $18: 3 n-3$ & $-0.88^{\star}$ & -0.43 & 0.05 & 0.02 & 0.12 \\
\hline$c 9, t 11-\mathrm{CLA}$ & $-0.97^{\star}$ & 0.18 & 0.11 & -0.09 & 0.01 \\
\hline$t 10, c 12-C L A$ & -0.65 & $0.71^{*}$ & 0.13 & -0.13 & -0.09 \\
\hline CLA others & -0.77 & 0.40 & -0.33 & -0.10 & 0.00 \\
\hline $20: 4 n-6$ & 0.63 & $-0.68^{*}$ & -0.21 & 0.17 & 0.04 \\
\hline Total cholesterol & -0.10 & -0.59 & -0.10 & $-0.63^{*}$ & -0.24 \\
\hline HDL-cholesterol & -0.32 & -0.01 & $-0.74^{*}$ & 0.14 & -0.35 \\
\hline LDL-cholesterol & -0.15 & -0.60 & -0.18 & -0.49 & -0.42 \\
\hline TAG & 0.40 & -0.05 & 0.44 & $-0.65^{*}$ & 0.45 \\
\hline Glucose & -0.01 & -0.38 & 0.27 & $0.63^{*}$ & -0.54 \\
\hline Insulin & $-0.50^{\star}$ & $-0.57^{\star}$ & 0.27 & -0.11 & -0.37 \\
\hline Adiponectin & -0.23 & 0.71 & 0.13 & -0.13 & $-0.48^{*}$ \\
\hline Leptin & $-0.75^{\star}$ & -0.61 & 0.17 & 0.04 & 0.08 \\
\hline Ghrelin & $0.63^{*}$ & 0.02 & -0.04 & -0.36 & 0.27 \\
\hline $\mathrm{IL}-1 \beta$ & $-0.77^{\star}$ & -0.43 & -0.03 & 0.18 & 0.17 \\
\hline IL-6 & -0.31 & -0.15 & $-0.68^{*}$ & -0.53 & -0.17 \\
\hline TNF- $\alpha$ & $-0.67^{\star}$ & 0.36 & -0.52 & 0.04 & 0.03 \\
\hline CRP & -0.10 & 0.38 & $0.71^{*}$ & -0.06 & -0.39 \\
\hline MCP-1 & -0.02 & 0.57 & -0.43 & 0.02 & -0.20 \\
\hline PAI-1 & 0.30 & $-0.76^{*}$ & 0.21 & -0.04 & -0.32 \\
\hline Portion of variance $(\%)$ & 43.85 & 19.63 & $10 \cdot 08$ & 7.64 & $6 \cdot 36$ \\
\hline Cumulative variance (\%) & 43.85 & 63.48 & 73.56 & $81 \cdot 2$ & 87.56 \\
\hline
\end{tabular}

CRP, C-reactive protein; MCP-1, monocyte chemoattractant protein-1; PAI-1, plasminogen activator inhibitor-1.

*The most significant loadings.

(rich in $18: 2 n-6)$ replaced CLA oil in the diets without supplementation, and so a reduction of $18: 2 n-6$ in CLAsupplemented groups was expected. This decrease probably also explain the reduction in $20: 4 n-6$ levels, an endogenous metabolite of $18: 2 n-6$. The incorporation of CLA isomers into adipose tissues did not reflect the CLA profile of dietary treatments, being the $t 10, c 12$-CLA less incorporated than the $c 9, t 11$-CLA isomer, as observed by other authors ${ }^{(33)}$. Apart from a possible endogenous synthesis in the rat, the $c 9, t 11$-CLA levels in adipose tissue were mostly provided by the ovine fat-enriched diet. Park et al. ${ }^{(34)}$ reported a clear decrease in stearoyl-CoA desaturase enzyme activity by CLA. In both adipose tissues, it was not observed a clear effect of CLA on $\Delta$ 9-indices (a proxy for stearoyl-CoA desaturase capability), but a CLA $\times$ fat interaction, meaning that CLA action depends on the fatty acid profile available in the diet.

In addition to the CLA ability to modulate adipokine metabolism affecting glucose and lipid metabolisms, namely, insulin sensitivity, other subgroups of fatty acids are capable of influencing these metabolisms, as well. In rats with hyperleptinaemia and hyperinsulinaemia, dietary $n-3$ PUFA caused a $40-50 \%$ reduction in plasma levels of leptin and insulin ${ }^{(13)}$. A recent work has demonstrated that $16: 0$ and $c 9-18: 1$ inhibited hepatic insulin signalling in hepatocyte cell cultures ${ }^{(14)}$. Nevertheless, there is insufficient knowledge about how fatty acid profiles of adipose tissue are correlated with serum metabolites concentration. In the present study, a PCA was carried out to explore the relationships between the deposition of individual fatty acids in adipose tissue and serum metabolites. The projection of variables in the PC1 $\times$ PC2 plane (Fig. 1), explaining a substantial percentage of the total variance $(63 \%)$, revealed some interesting associations. Fatty acids distribution in the graph can be fairly interpreted by its common dietary origin, with quadrants $\mathrm{A}$ and $\mathrm{D}$ related with saturated fat source and quadrants A and B with CLA supplementation. Adiponectin was located close to the $t 10, c 12$-CLA isomer and, on the opposite, PAI-1, which in turn was near $20: 4 n-6$ and its precursor $18: 2 n-6$. Indeed, a study in human subjects showed that dietary $18: 2 n-6$ and 20:4n-6 were positively associated with PAI-1 activity ${ }^{(35)}$. In relation to $c 9, t 11-C L A$, this isomer appeared inversely related to $\mathrm{TAG}$, which corroborates the reduction on plasma TAG levels in obese rodents fed this isomer ${ }^{(36,37)}$. TNF- $\alpha$ was located near the 14:0,c7-16:1 and $c 9, t 11$-CLA in the lower region of quadrant $\mathrm{A}$, reflecting the influence of both ovine fat and CLA supplementation. Leptin and insulin were located in left region of quadrant $\mathrm{D}$, together with $18: 0$, $t 10+t 11-18: 1,18: 3 n-3$, suggesting that they are mainly related to fatty acids in ovine fat diets. Besides the fact that $16: 0$ has been associated with inflammation ${ }^{(38,39)}$, in the present study, this predominant SFA in palm oil diets was located contrarily to IL-1 $\beta$ and IL-6. The location of ghrelin in the border of quadrants $\mathrm{B}$ and $\mathrm{C}$ showed that this hormone is 


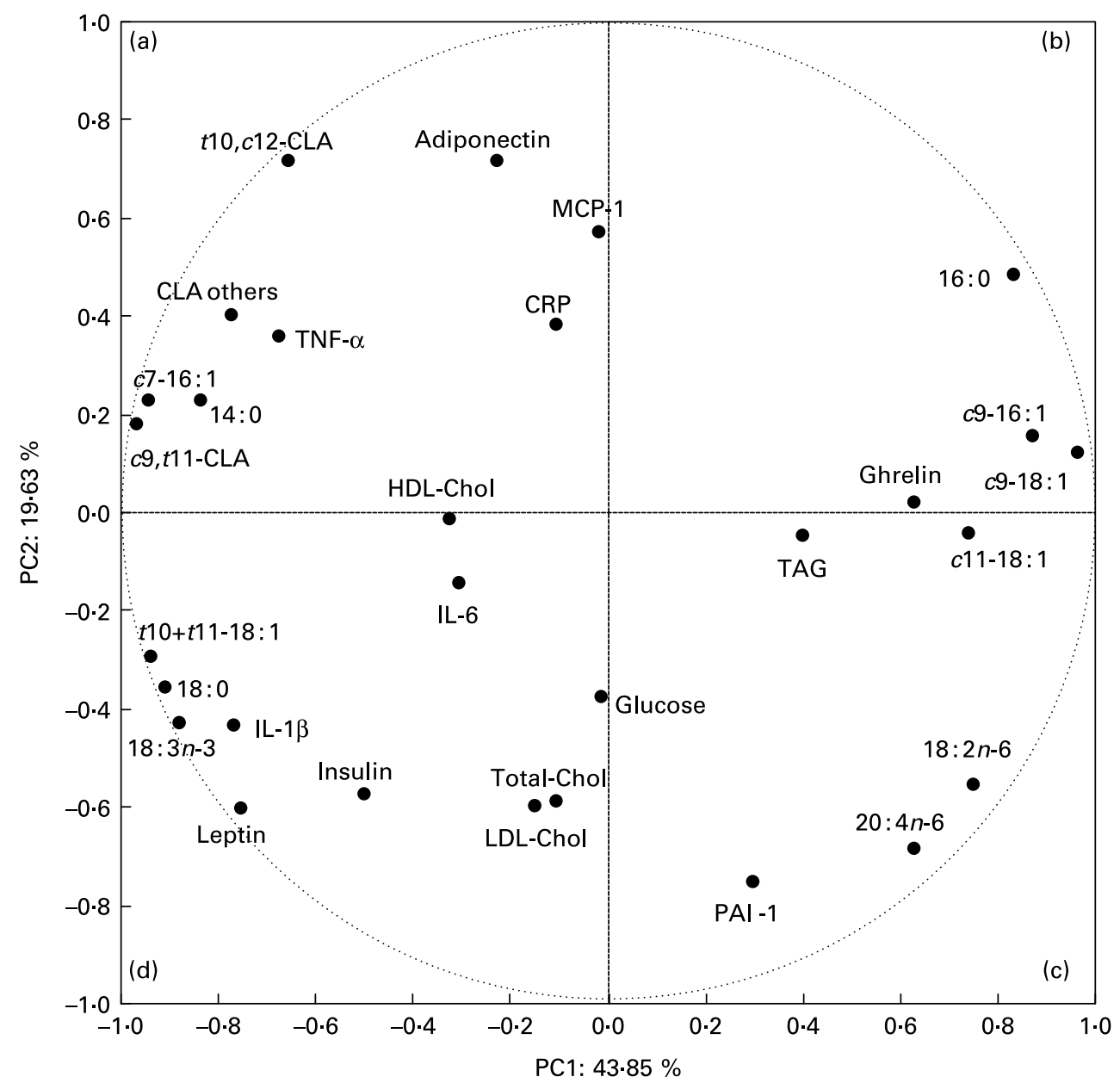

Fig. 1. Projection of the variables (average of fatty acids percentages from epididymal and retroperitoneal adipose tissues and contents of serum metabolites) in the plane defined by the two first principal components (PC1 and PC2 loadings plot). CLA, conjugated linoleic acid; c9,t11-CLA, cis-9,trans-11-CLA; t10,c12-CLA, trans-10,cis-12-CLA; CRP, C-reactive protein; HDL-Chol, HDL-cholesterol; LDL-Chol, LDL-cholesterol; MCP-1, monocyte chemoattractant protein-1; PAI-1, plasminogen activator inhibitor-1; Total-Chol, total-cholesterol.

mainly associated with dietary palm oil. The variables located near the origin of the PC1 and PC2 axis were not related with any of the studied factors. The associations between $t 10, c 12$ CLA, positively with adiponectin and negatively with PAI-1, reinforce our belief that $t 10, c 12-C L A$, but not $c 9, t 11-C L A$, is the main isomer responsible for CLA effects in the present work. As it is not possible to draw definite causal relationships with these exploratory techniques of data analysis, some associations should be exploited in well-directed experimental designs. For instance, the effects of $18: 2 n-6$ and $c 9-18: 1$ on serum ghrelin concentrations should be further evaluated.

In the present study, the specific effects observed for ovine fat treatments may be attributed to the different fatty acid composition of the diets containing fat from vegetable or animal sources (Table 1). In concrete, the influence on insulin resistance and pro-inflammatory profile can be mainly due to the imbalance between the pro-inflammatory SFA (sum of 16:0 and 18:0, 40-42 v. 34\%, for vegetable and animal fat diets, respectively) and the anti-inflammatory MUFA (percentage of $c 9-18: 1,32-35 v$. 21-22\%, for vegetable and animal fat diets, respectively) present in the diet ${ }^{(38)}$. Concerning trans fatty acids, $t 11-18: 1$ is the predominant in animal fats ( $9 \%$ of total fatty acids methyl esters), and is precursor of $c 9, t 11-$ CLA by endogenous conversion in tissues $^{(40)}$. In fact, it was recently reported that $t 11-18: 1$, in contrast to $t 10-18: 1$ isomer, is neutral or even beneficial to aortic lipid deposition in rabbits ${ }^{(41)}$. Moreover, ovine fat diets contain minor amounts of trans fatty acids derived from rumen biohydrogenation, trans and cis isomers of oleic acid and conjugated and non-conjugated trans isomers of linoleic acid, not discriminated in the present study, which can display additional roles on these effects.

\section{Conclusions}

The results suggest that CLA supplementation of diets rich in saturated fats and cholesterol has some beneficial effects in obese Zucker rats by increasing adiponectin and decreasing PAI-1 serum levels, as well as alleviating hepatic steatosis through hepatic lipids reduction. However, this decrease does not seem to be enough to improve insulin sensitivity. The multivariate analysis suggested that CLA effects observed on adiponectin and PAI-1 levels can be mainly attributed to the $t 10, c 12$-CLA isomer. On the other hand, diets enriched in ovine fat appear to promote an increase in serum concentrations of some pro-inflammatory cytokines, also increasing 
insulin resistance. The present work questions the usefulness of CLA to prevent obesity in Western societies, whereas high intake of animal saturated fats is prevalent. Nonetheless, the combination of CLA and saturated fat diets from vegetable origin seems to attenuate prejudicial effects promoted by animal fats.

\section{Acknowledgements}

The authors acknowledge Clínica Médica e Diagnóstico Dr Joaquim Chaves (Algés, Portugal) for the technical assistance regarding the serum lipids determination. The present study was supported by FCT POCTI/CVT/2002/44750 and PTDC/CVT/2006/66 114 grants. S. V. M., P. A. L. and S. P. A. are the recipients of FCT individual fellowships SFRH/BD/2005/2256, SFRH/BPD/2005/23931 and SFRH/ BD/2007/37 793, respectively. S. V. M., P. A. L. and C. M. A. performed the animal experiment, tissue sampling, laboratory work and prepared the manuscript. P. O. R. was responsible for Luminex XMAP analysis. S. P. A. and R. J. B. B. were responsible for fatty acid analysis. R. M. A. P. performed the biochemistry serum profile. S. V. M. and R. J. B. B. performed the statistical analysis. M. F. C. and J. A. M. P. were responsible for interpretation of the results, preparation of the manuscript and design of the study. All authors read and approved the findings of the study.

There are no conflicts of interest.

\section{References}

1. Murdolo G \& Smith U (2006) The dysregulated adipose tissue: a connecting link between insulin resistance, type 2 diabetes mellitus and atherosclerosis. Nutr Metab Cardiovasc Dis 16, S35-S38.

2. Fain JN (2006) Release of interleukins and other inflammatory cytokines by human adipose tissue is enhanced in obesity and primarily due to the nonfat cells. Vitam Horm 74, 443-477.

3. Wang P, Mariman E, Renes J, et al. (2008) The secretory function of adipocytes in the physiology of white adipose tissue. J Cell Physiol 216, 3-13.

4. Vendrell J, Broch M, Vilarrasa N, et al. (2004) Resistin, adiponectin, ghrelin, leptin and proinflammatory cytokines: relationships in obesity. Obes Res 12, 962-971.

5. Dolinková M, Dostálová I, Lacinová Z, et al. (2008) The endocrine profile of subcutaneous and visceral adipose tissue of obese patients. Mol Cell Endocrinol 291, 63-70.

6. Trayhurn P (2005) Adipose tissue in obesity - an inflammatory issue. Endocrinology 146, 1003-1005.

7. Yamasaki M, Ikeda A, Oji M, et al. (2003) Modulation of body fat and serum leptin levels by dietary conjugated linoleic acid in Sprague-Dawley rats fed various fat-level diets. Nutrition 19, 30-35.

8. Martins SV, Lopes PA, Alfaia CM, et al. (2007) Contents of conjugated linoleic acid isomers in ruminant-derived foods and estimation of their contribution to daily intake in Portugal. Br J Nutr 98, 1206-1213.

9. Wang Y, Nagao K, Inoue N, et al. (2006) Isomer-specific antiobese and hypolipidemic properties of conjugated linoleic acid in obese OLETF rats. Biosci Biotechnol Biochem 70, 355-362.

10. Park Y, Albright KJ, Storkson JM, et al. (2007) Conjugated linoleic acid (CLA) prevents body fat accumulation and weight gain in an animal model. $J$ Food Sci 72, S612-S617.

11. Wendel AA, Purushotham A, Liu L-F, et al. (2008) Conjugated linoleic acid fails to worsen insulin resistance but induces hepatic steatosis in the presence of leptin in ob/ob mice. $J$ Lipid Res 49, 98-106.

12. Halade GV, Rahman M \& Fernandes G (2009) Differential effects of conjugated linoleic acid isomers in insulin-resistant female C57BL/6J mice. J Nutr Biochem (Epublication ahead of print version 6 May 2009).

13. Ukropec J, Reseland JE, Gasperikova D, et al. (2003) The hypotriglyceridemic effect of dietary $n-3$ FA is associated with increased $\beta$-oxidation and reduced leptin expression. Lipids 38, $1023-1029$.

14. Kim K, Kim HY, Son EJ, et al. (2009) Oleic acid inhibits hepatic insulin signaling through deregulation of STAT3 activation and C/EBPalpha expression. Cell Signal 21, 1269-1276.

15. Montague CT, Farooqi IS, Whitehead JP, et al. (1997) Congenital leptin deficiency is associated with severe earlyonset obesity in humans. Nature 387, 903-908.

16. Kasiske BL, O’Donnell MP \& Keane WF (1992) The Zucker rat model of obesity, insulin resistance, hyperlipidemia, and renal injury. Hypertension 19, Suppl. I, I110-I115.

17. Akahoshi A, Koba K, Enmoto R, et al. (2005) Combined effects of dietary protein type and fat level on the body fat-reducing activity of conjugated linoleic acid (CLA) in rats. Biosci Biotechnol Biochem 69, 2409-2415.

18. Hu FB, Manson JE \& Willet WC (2001) Types of dietary fat and risk of coronary heart disease: a critical review. $J \mathrm{Am}$ Coll Nutr 20, 5-19.

19. Jerónimo E, Alves SP, Prates JAM, et al. (2009) Effect of dietary replacement of sunflower oil with linseed oil on intramuscular fatty acids of lamb meat. Meat Sci 83, 499-505.

20. Friedewald WT, Levy RI \& Fredrickson DS (1972) Estimation of the concentration of low-density lipoprotein cholesterol in plasma, without use of the preparative ultracentrifuge. Clin Chem 18, 499-502.

21. Covaci A, Voorspoels S, Thomsen C, et al. (2006) Evaluation of total lipids using enzymatic methods for the normalization of persistent organic pollutant levels in serum. Sci Total Environ 366, 361-366.

22. Matthews DR, Hosker JP, Rudenski AS, et al. (1985) Homeostasis model assessment: insulin resistance and beta-cell function from fasting plasma glucose and insulin concentrations in man. Diabetologia 28, 412-419.

23. Fritshe J, Fritsche S, Solomon MB, et al. (2000) Quantitative determination of conjugated linoleic acid isomers in beef fat. Eur J Lipid Sci Technol 102, 667-672.

24. Christie WW, Sébédio JL, Juanéda P, et al. (2001) A practical guide to the analysis of conjugated inoleic acid (CLA). Inform 12, $147-152$.

25. Raes K, Haak L, Balcaen A, et al. (2004) Effect of linseed feeding at similar linoleic acid levels on the fatty acid composition of double-muscled Belgian Blue young bulls. Meat Sci 66, 307-315.

26. Nagao K, Inoue N, Wang Y-M, et al. (2005) Dietary conjugated linoleic acid alleviates nonalcoholic fatty liver disease in Zucker ( falfa) rats. J Nutr 135, 9-13.

27. Noto A, Zahradka P, Yurkova N, et al. (2006) Conjugated linoleic acid reduces hepatic steatosis, improves liver function, and favorably modifies lipid metabolism in obese insulin-resistant rats. Lipids 41, 179-188.

28. Gudbrandsen O, Rodriguez E, Wergedahl H, et al. (2009) Trans-10,cis-12-conjugated linoleic acid reduces the hepatic triacylglycerol content and the leptin mRNA level in adipose tissue in obese Zucker falfa rats. Br J Nutr 102, 803-815.

29. Sisk MB, Hausman DB, Martins RJ, et al. (2001) Dietary conjugated linoleic acid reduces adiposity in lean but not obese Zucker rats. J Nutr 131, 1668-1674. 
30. Noto A, Zahradka P, Yurkova N, et al. (2007) Dietary conjugated linoleic acid decreases adipocyte size and favorably modifies adipokine status and insulin sensitivity in obese, insulin-resistant rat. Metabolism 56, 1601-1611.

31. Alessi MC, Bastelica D, Mavri A, et al. (2003) Plasma PAI-1 levels are more strongly related to liver steatosis than to adipose tissue accumulation. Arterioscler Thromb Vasc Biol 23, $1262-1268$.

32. Munday JS, Thompson KG \& James KA (1999) Dietary conjugated linoleic acids promote fatty streak formation in the C57BL/6 mouse atherosclerosis model. Br J Nutr 81, 251-255.

33. Kelley DS, Bartolini GL, Newman JW, et al. (2006) Fatty acid composition of liver, adipose tissue, spleen, and heart of mice fed diets containing $t 10, c 12$ and $c 9, t 11$ - conjugated linoleic acid. Prostag Leukotr Ess 74, 271-282.

34. Park Y, Storkson J, Ntambi JM, et al. (2000) Inhibition of hepatic stearoyl-CoA desaturase activity by trans-10, cis-12 conjugated linoleic acid and its derivates. Biochim Biophys Acta 1486, 285-292.

35. Byberg L, Smedman A, Vessby B, et al. (2001) Plasminogen activator inhibitor-1 and relations to fatty acid composition in the diet and in serum cholesterol esters. Arterioscler Thromb Vasc Biol 21, 2086-2092.
36. Roche HM, Noone E, Sewter C, et al. (2002) Isomer-dependent metabolic effects of conjugated linoleic acid - insights from molecular markers sterol regulatory element-binding protein1c and LXR $\alpha$. Diabetes 51, 2037-2044.

37. Ryder JW, Portocarrero CP, Song XM, et al. (2001) Isomerspecific antidiabetic properties of conjugated linoleic acid improved glucose tolerance, skeletal muscle insulin action, and UCP-2 gene expression. Diabetes 50, 1149-1157.

38. Kennedy A, Martinez K, Chuang C-C, et al. (2009) Saturated fatty acid-mediated inflammation and insulin resistance in adipose tissue: mechanisms of action and implications. J Nutr 139, $1-4$.

39. Petersson H, Lind L, Hulthe J, et al. (2009) Relationships between serum fatty acid composition and multiple markers of inflammation and endothelial function in an elderly population. Atherosclerosis 203, 298-303.

40. Corl BA, Barbano DM \& Bauman DE (2003) Cis-9,trans-11 CLA derived endogenously from trans-11 18:1 reduces cancer risk in rats. J Nutr 133, 2893-2900.

41. Roy A, Chardigny JM, Bauchart D, et al. (2007) Butters rich either in trans-10-C18:1 or in trans-11-C18:1 plus cis-9,trans11 CLA differentially affect plasma lipids and aortic fatty streak in experimental atherosclerosis in rabbits. Animal 1, $467-476$. 